\title{
Article 11 \\ Applicability of Air Regulations
}

\begin{abstract}
Subject to the provisions of this Convention, the laws and regulations of a contracting State relating to the admission to or departure from its territory of aircraft engaged in international air navigation, or to the operation and navigation of such aircraft while within its territory, shall be applied to the aircraft of all contracting States without distinction as to nationality, and shall be complied with by such aircraft upon entering or departing from or while within the territory of that State.
\end{abstract}

\section{Contents}

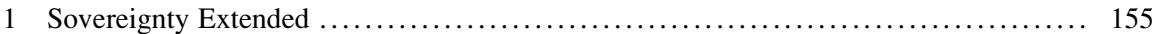

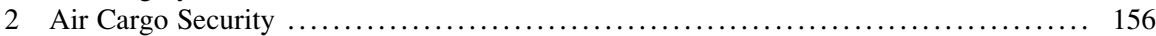

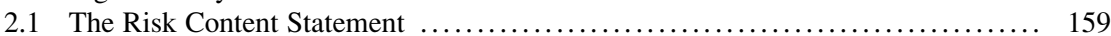

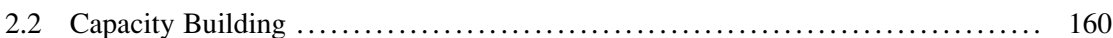

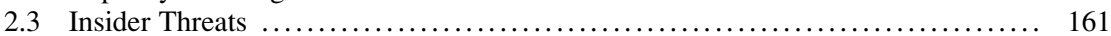

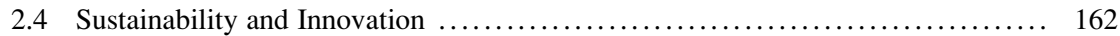

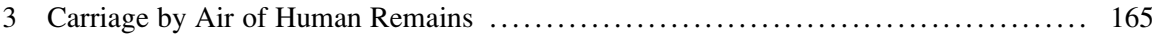

3.1 The Berlin Agreement of 1937 ...................................... 167

3.2 Agreement on the Transfer of Corpses (Strasbourg-1973) ................. 168

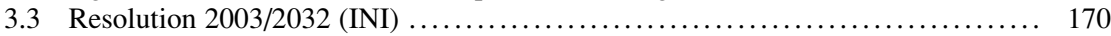

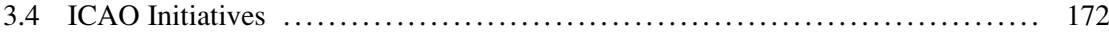

3.4.1 The Council ........................................... 172

3.4.2 Annexes 9, 17 and 18 to the Chicago Convention .................. 173

3.4.3 IATA, WHO and United States Guidelines ...................... 175

\section{Sovereignty Extended}

At its 2nd Assembly (Geneva, 1-21 June 1948) the Council was directed through Resolution A2-45 which revised an earlier Resolution A1-30 to establish procedures for the reporting of individual cases of alleged breaches of, or noncompliance with national aeronautical regulations and the corrective action taken by States in such cases, including adoption of measures to ensure that airmen of their respective States would be familiar with the regulations of other Contracting States and with rules in force over the high seas. The Council, in its Annual Report to the 7th Session of the Assembly (Brighton, 16 June-6 July 1953) in formed the Assembly that:

After further study of the difficulties involved in finding a practicable and effective procedure, the subject has been dropped, at least for the time being ${ }^{1 "}$.

${ }^{1}$ Doc 7367, A7-P/1. 
Resolution A2-45 was eventually declared to be no longer in force by Resolution A16-1 at the 16th Session of the Assembly (Buenos Aires, 3-26 September 1968). It must be noted that Annex 17 (security) to the Chicago Convention has an analogous provision (presumably stemming from Article 11) where Recommended Practice 6.1.2 provides that each ICAO member State should require the operators of aircraft of its registry to conform to the international civil aviation security requirements of those States into which they operate. Article 11 therefore has a strong link to security.

The carriage of dangerous goods into a country is a case in point, examples being the air cargo security and the carriage by air of human remains and dangerous substances.

\section{Air Cargo Security}

The air cargo industry is a 60 billion dollar business and passenger-accompanied air cargo is a major profit maker accounting for approximately $15 \%$ of the industry's overall revenue. At a high level aviation security conference held by the International Civil Aviation Organization in September 2012, ICAO advised that civil aviation was estimated to grow by $6 \%$ in 2013; $6.4 \%$ in 2014; and $4.9 \%$ on an annual basis until 2020, such growth being encouraging to the air transport industry from an economic perspective. At the same time, ICAO cautioned that this growth may not necessarily halt the persisting threat of unlawful interference with civil aviation and that the threat will evolve into a complex web of activity as new innovative methods of attack are conceived. This brought to bear the compelling need to address the growing vulnerabilities of the air transport system and the sustainability of aviation security.

In this context the conference noted that air cargo security, its sustainability and the need for innovative approaches to risk management were considered paramount and that it was essential that a global legal and regulatory system should govern the carriage of air cargo, where carriers would observe and fulfil requirements for security of each State they operated air services into and out of.

The High Level Conference on Aviation Security, convened by the International Civil Aviation Organization from 12 to 14 September 2012 in Montreal was attended by over 700 participants representing 132 of ICAO's 191 member States, and 23 Intergovernmental and industry international and regional organizations. The Conference focused on three overarching themes on cargo security, sustainability of security measures and innovation in addressing threats to aviation security.

The Conference recalled the events of 29 October 2010 when terrorists exploited vulnerabilities in the air cargo security system to introduce improvised explosive devices intended to destroy aircraft in flight, and endorsed certain principles on air cargo and mail security. One principle was that a strong, sustainable and resilient air cargo security system is essential and that the threat is to the air cargo system as a whole and risk-based consideration must be given to strengthening security measures across all aspects of the system, including enhancing the ability to recover from a 
major disruption. Another was that appropriate security controls should be implemented at the point of origin. Cargo and mail should come from a secure supply chain or be screened and, in either case, protected throughout the entire journey, including at transfer and transit points. At points of transfer, States should satisfy themselves that security controls previously applied to cargo and mail meet ICAO Standards. In doing so, they should avoid unnecessary duplication of security controls.

An important milestone in this regard was the recognition that air cargo advanced information for security risk assessment is a developing area that enhances air cargo security, particularly in the context of express delivery carriers such as FEDEX, UPS, DHL Express and TNT Express who carry around thirty million shipments daily, which typically contain high-value added, time-sensitive cargo. These carriers guarantee the timely delivery of these vast volumes of shipments, ranging from same-day delivery to $72 \mathrm{~h}$ after pick-up, virtually anywhere in the world. They operate in 220 countries and territories.

The conference noted that a real risk in the area of cargo and mail security would arise when an express delivery carrier experiences a technical problem in an aircraft and is forced to transfer cargo to a passenger carrier, in which instance strict supply chain standards should be adhered so that the risk in the transfer of cargo could be obviated.

Participants agreed that it was essential that solid standards and mutual recognition programmes be in place in order to make sure that States all along an air cargo supply chain satisfy themselves that air cargo is secure, and so let it flow unimpeded. Such standards and recommended practices should allow for the speedy transit and transhipment of legitimate air cargo worldwide, through any combination of air routes and transit or transhipment points.

Another risk factor considered by the Conference was the insider threat and the need to implement $100 \%$ screening of persons other than passengers. This includes personnel at the airport, visitors and others who do not carry a boarding card. The Conference was reminded that States needed to acknowledge that the roles of people other than passengers that are working in civil aviation can present particular vulnerabilities that should be addressed.

It was also noted that there is already an ICAO Standard which requires each State to ensure that persons other than passengers, together with items carried, being granted access to security restricted areas are screened; however, if the principle of $100 \%$ screening cannot be accomplished, other security controls, including but not limited to proportional screening, randomness and unpredictability, should be applied in accordance with a risk assessment carried out by the relevant national authorities.

One of the recommendations put forward at the Conference was to establish more airport authorities with increased aviation security expertise. In this regard it was noted that comprehensive background checks of all personnel selected for hire/ employment at an airport need to be carried out by the relevant State's security agencies based on risk assessment. In addition, re-vetting of airport workers such as cleaners, duty free shop personnel, catering staff and concessionaires must be carried out frequently in order to mitigate collusion to commit acts of unlawful interference. 
The author is of the view that if aviation security concerning cargo and mail were to be addressed in a results-based manner, there are two key areas that need to be enforced: sustainability and innovation. "Sustainable aviation security" can be defined as the detection and prevention of, and response to and recovery from, acts or attempted acts of unlawful interference with civil aviation, utilizing means that can be sustained by the entity or entities responsible for the period of time required. It is worth noting a number of important inter-related policy principles and practices that can contribute to the achievement of sustainable aviation security. These and other means can, more broadly, support the development of a sound and economically-viable civil aviation system. The starting point for consideration of any security measure must be a risk assessment. Such risk assessments, carried out objectively by appropriate security authorities on a continuous basis and informed by available and relevant information, including security intelligence, help assure that new or revised security measures are justified, aligned with actual needs and are proportionate to the level of risk.

The Conference recognized that the sustainability of aviation security measures and arrangements is an important strategic issue for all entities with aviation security-related responsibilities. It noted that risk-based security measures, outcomes-focused security measures, rationalization of security measures, optimization of technology, mutual recognition of equivalence and one-stop security, harmonization, and preparedness for crisis events are policy principles and practices whose implementation can contribute significantly to the sustainability of aviation security measures and arrangements.

From the time aviation was used as a weapon of mass destruction on 11 September 2001, there have been 75 terrorist attacks on aircraft and airports worldwide which have resulted in 157 deaths up to the end of 2011. When one compares this statistic to other modes of transport, such as trains and buses, one notes that there have been approximately 2,000 attacks and about 4,000 deaths resulting. On this basis, aviation has been fortunate. However, one cannot be complacent. The terrorist anchors himself on the Displacement Theory, moving from one mode of attack to another when the going gets bad. The 9/11 attacks on buildings turned to attacks on airports and then onwards to cargo. Examples go back to the 1980s where, in the early 1980s, aircraft were attacked through the cargo hold (recalling just three instances when aircraft of Air India and PANAM were blown up in midair as well as the attack on the Airlanka aircraft) to using aircraft as weapons of mass destruction in 2001, to attacking airports in the 1990s. Recalling the events of 29 October 2011 discussed above, one could argue that unlawful interference with civil aviation has turned full 360 degrees and has seemingly returned to attacks on cargo.

The Conference viewed with approval the ICAO Risk Content Statement and endorsed the Declaration adopted at the 37th ICAO Assembly Session convened by ICAO from 28 September to 8 October 2010, which, inter alia called for the strengthening of security screening procedures, enhancement of human factors and utilization of modern technologies to detect prohibited articles and support of research and development of technology for the detection of explosives, weapons 
and prohibited articles in order to prevent acts of unlawful interference. The Declaration also calls on all Member States to share best practices and information on a range of key aviation security matters, including threat-based risk assessments.

\subsection{The Risk Content Statement}

The Risk Content Statement submitted to the Conference by ICAO was entirely based on a global risk based approach which advocated a robust methodology for national risk assessment. It aims at providing a description of the global risk picture; assisting States in their efforts to protect air transportation and prevent its use for unlawful acts; presenting high-level statements for an improved approach in creating and maintaining State national civil aviation security programmes; and assisting ICAO in improving Standards and Recommended Practices (SARPs) and guidance material. The Statement focused the attention of ICAO member States to Standard 3.1.3 of Annex 17 to the Convention on International Civil Aviation (Chicago Convention) which requires each State to keep under constant review the level of threat to civil aviation within its territory, and establish and implement policies and procedures to adjust relevant elements of its national civil aviation security programme, based on a security risk assessment carried out by relevant national authorities. The Conference, based on this fundamental premise, recognized that a reasonably designed risk-based approach is one by which States identify the criteria to measure potential criminal activities, principally from terrorism. The identification of risks permits States to determine and implement proportionate measures and controls to mitigate against each risk type.

The Statement exhorted member States of ICAO to share information based on the premise that in conducting a risk assessment, it is necessary to assemble information about the threat. Such information may come from a variety of sources, such as those relating to: actual incidents, including successful or unsuccessful attacks on aviation, which provide information on proven terrorist methodologies; closed sources, from primarily counter-terrorist intelligence, which may be gathered by intelligence, law enforcement and other agencies of States; and open sources, which may include publicly available information on unusual or suspicious occurrences and the availability of items that could be used for terrorist purposes, and any other information that may contribute to the threat picture.

The Statement also highlights the insider threat as being of compelling significance. It emphasizes the danger of vulnerability associated with insiders which may be considered greater if they have access to the last layer of security in a way that a passenger does not, and points out that the likelihood associated with insiders might be less if they have already been subject to vetting and selection procedures and/or screening. It cautions that the consequence of a threat associated with insiders might be greater if an insider has access deeper within the system. For instance, an insider could perpetrate a more credible and thus more disruptive hoax. In summary, the Statement explains that the methodology involves considering each role within the system and whether it offers a particular tactical advantage in relation to 
each threat type or whether it poses the same issues as passengers, and that, in applying this methodology, it is possible to consider insider vulnerabilities as part of an integrated risk assessment.

Finally, the Risk Content Statement identifies risk assessment as a process which evaluates risk by threat identification, i.e. identifying the threat scenario, consisting of a defined target (e.g. airport terminal or aircraft), as well as the means and method of possible attack (e.g. attack by passenger using an improvised explosive device, or attack by an insider using weapon, etc.); likelihood i.e. considering the probability of the threat occurring; consequence-assessing the nature and scale of likely impacts associated with a successful attack, including consideration of human, economic, political and reputational factors (based on a reasonable worstcase scenario); vulnerabilities, i.e. evaluating the effectiveness and vulnerabilities of current security measures (i.e. security strengths and weaknesses of SARPs) in mitigating the potential threat scenario identified; and residual risk i.e. assessing the remaining risk of that type of attack being successfully carried out against that target, to enable a judgement to be made as to whether that is acceptable in risk management terms.

\subsection{Capacity Building}

The High Level Security Conference noted that capacity building on an international scale was critical to a risk based approach for air cargo security. In this regard it was recognized that an international capacity building strategy for air cargo and mail security would draw on the ICAO Assistance and Capacity Building Strategy for Aviation Security, and allow for targeted assistance for States in need. This Strategy would be guided by the ICAO security audit results, where air cargo and mail security has been identified as a priority need. The Strategy would include a proposal to coordinate bilateral and multilateral capacity building initiatives regionally, as well as amongst international organizations such as the World Customs Organization (WCO) and the Universal Postal Union (UPU) in order to align such initiatives, maximize limited resources, and avoid duplication of efforts. The development of such a strategy would also be in line with the ICAO Comprehensive Aviation Security Strategy (ICASS) 2011-2016 that was endorsed at the 37th ICAO Assembly in 2010.

In this regard the Conference viewed favourably the idea that any new arrangements must recognize that many donor states engage in aviation security capacity building for specific national interest reasons, generally related to the nature of flights into donor states. This is understandable and, in fact, is a concept which drives many bilateral aviation security efforts across the globe. In encouraging this capacity building to continue, the proposed framework seeks to better coordinate and inform its development by building on existing and future Government-toGovernment arrangements with targeted industry-to-industry capacity building efforts, and using ICAO-sponsored capacity building where regional "gaps" in bilateral, multilateral and industry capacity building efforts are identified. 
The reality that capacity building requires a long-term commitment and should be focused on "regular/repeated engagement", rather than the provision of one-off courses on an irregular basis, was recognized, together with the fact that effective capacity building takes years and will only succeed when issues of trust, mutual respect and culture are addressed and fostered on an on-going basis. The Conference endorsed the development of an International Capacity Building Strategy specific to air cargo and mail security, to aid those ICAO member States that require assistance to adequately implement enhanced ICAO air cargo and mail security standards. This Strategy was to be aligned with the ICAO Assistance and Capacity Building Strategy for Aviation Security, and avoid duplication of efforts. It also encouraged all ICAO Contracting States to further support the Secretariat in its efforts to provide capacity building assistance based on USAP audit results, subject to the consent of the State(s) receiving assistance, focusing on air cargo and mail where it has been identified as a priority; and urged other entities within the air cargo environment to continue taking action to effectively secure those sections of the supply chain in which they operate.

\subsection{Insider Threats}

A third element addressed within the parameters of the risk based approach was the insider threat and the need for screening of persons other than passengers. The Conference considered as the basis for discussion Standard 4.2.6 to Annex 17 to the Chicago Convention which, through Amendment 12 to the Annex (which became applicable on 1 July 2011), states that each Contracting State is required to ensure that persons other than passengers, together with items carried, being granted access to security restricted areas are screened; however, if the principle of $100 \%$ screening cannot be accomplished, other security controls, including but not limited to proportional screening, randomness and unpredictability, shall be applied in accordance with a risk assessment carried out by the relevant national authorities.

The above provision notwithstanding, the Conference recognized that it was indeed very difficult to preclude, detect and face an act of unlawful interference carried out with the internal support of persons who have access to securityrestricted areas, even though such persons may have had their records verified. The danger and risk were compounded by the fact that such persons usually have access to sterile lounges and other security-restricted areas where they have the opportunity to mingle with passengers and therefore could well interfere with their carry-on baggage and/or the checked baggage already inspected. They also have access to aircraft during ground and pre-flight services. One participating State suggested that in all access control points, conditions should be created securing that $100 \%$ of persons who are not passengers, as well as the articles transported, are subject to security inspections with whatever of the different means available for this purpose, including manual inspection. 
Some national practices submitted to the Conference were: (a) supervise or accompany daily/seasonal workers in the restricted security area; (b) closely examine all officials, employees or staff entering the restricted security area; closely examine all Janitors before permitting them to enter the aircraft; oversee the restricted security areas and facilities related to flight operations by patrolling periodically or continuous surveillance using CCTV; inspect all cabin carry-on, baggage and cargo as well as food (catering items) and equipment required and sold in flight (stores) and watch them before and during the loading onto the aircraft; oversee the process of boarding passengers and loading of goods; aircraft security check before departure (pre-flight security check); supervise, control and update the permit issuance and use of appropriate entry of airport, including applying background checks and stop list procedure; implement security awareness training for all airport pass applicants; carry out internal and external quality control regularly based on risk assessment; and be aware of religious, social and cultural approach among stakeholders.

\subsection{Sustainability and Innovation}

The Conference recognized that the sustainability of aviation security measures and arrangements is an important strategic issue for all entities with aviation securityrelated responsibilities and that risk-based security measures, outcomes-focused security measures, rationalization of security measures, optimization of technology, mutual recognition of equivalence and one-stop security, harmonization, and preparedness for crisis events are policy principles and practices whose implementation can contribute significantly to the sustainability of aviation security measures and arrangements.

The need for each State to carry out continuous risk assessments as a preliminary measure was considered paramount for the sustainability of security. One view was that aviation security has to be sustained in a balanced manner so that, on the one hand, applying security measures to mitigate identified threats, and on the other hand, the essential task of facilitating operations, passengers' experience and trade could be ensured. Security should not accumulate layer upon layer of controls and associated costs, but should rather ensure the sustainability of the system from the perspectives of cost, efficiency, and acceptability by passengers and air transport operators, which should be a central consideration when designing security processes. Another means of achieving sustainability is at transfer points where security controls are known to have been performed effectively at the point of origin. The Conference took note of the fact that, in such instances, the concept of "One Stop Security" should be advanced, where ICAO Member States, by virtue of recognising the equivalence of each other's aviation security regimes, can allow incoming passengers, baggage and cargo to transfer onto a connecting flight without being subjected, once again, to the same security controls as at the point of origin. The conclusion of such "One Stop Security" arrangements remains an issue to be addressed Member State to Member State. 
One proactive suggestion towards achieving and retaining sustainability was to follow the practice of reciprocal acceptance of equivalent security measures across the board, with due regard to the principle of host State responsibility, as envisaged by the Chicago Convention. In that respect, it was suggested that the need for any one State to require extra security measures of another State can be avoided by working together to align international requirements to the global threat environment. A further recommendation was that this approach should be reflected in Annex 17 to the Chicago Convention which deals with the subject of security.

The Conference was called upon to endorse a coordinated response to security incidents and threats whereby States could collectively accept, without derogating a State's freedom to take its own measures, the measures adopted by one State as a global norm if that norm were to be consistent with the Standards and Recommended Practices of Annex 17 and provided such recognition was accepted as such by ICAO.

Incontrovertibly, innovation in air cargo security lies in two areas: advancement of technology; and intelligence. In the field of air cargo security the ICAO Conference showed a marked deficiency of discussion. It is submitted that, critical to a discussion of technology and innovation is the subject of supply chain security. Preeminent among technological progress is the need to establish basic security packaging mandates for shippers. Cargo is either being flown or stored at any given point in time and therefore both phases must be covered in the tracking and identification of cargo. Hoffer recommends:

Courier boxes and envelopes supplied by carriers should be required to have an original number and (if possible) a tamper-evident seal and markings (tied to the bill of lading), so that it is harder to replace a package with a similar box. Recipients would have the ultimate responsibility to compare manifest numbers with packages before accepting them.

Air cargo can be loaded individually or in bulk form from $1 \mathrm{~kg}$ to a weight of several tons and can be loaded on various platforms such as unit load devices (ULDs) crates and assembled pallets. Several technologies are used at present in ensuring cargo security. These may vary between explosive detection devices, explosive trace detection computer aided tomography and X-ray, in addition to certified canine teams. The Transportation Security Administration (TSA) has identified such advanced technologies as XR/PFNA X-ray systems with pulsed fast neuron analysis; pressure activated sampling systems, quadruple resonance and miniature explosive and toxic chemical detector utilizer sensors.

In the context of military intelligence, the author submits that as a mirror reflection of the "known shipper" and "known consignor" practice, military intelligence be employed to track and identify unknown consignors as well as insiders. Taking into consideration the aircraft bombings that have taken place (some of which have been discussed in this article) it is fair to conclude that most of these attacks were perpetrated by groups of incendiary persons. Military intelligence, which essentially is information relating to the armed forces of a foreign country that is significant to the planning and conduct of another country's military doctrine, policy, and operations, largely penetrates such groups and could be effectively used to take pre-emptive and preventive measures against threats to air cargo security. 
It is eminently clear that the glue that binds the elements discussed above, including those that relate to the global supply chain, is law and practice. These are already in place in principle. For instance, Standard 4.6.1 of Annex 17 requires each Contracting State to ensure that appropriate security controls, including screening where applicable, are applied to cargo and mail, prior to their being loaded onto an aircraft engaged in passenger commercial air transport operations. The operative words here are "security controls" which brings to bear the reality that different States could have different security controls and that they should be harmonized in ensuring supply chain security and global security standards. Screening and examination of cargo and mail are paramount to this consideration.

Standard 4.6.2 requires that each Contracting State establish a supply chain security process, which includes the approval of regulated agents and/or known consignors, if such entities are involved in implementing screening or other security controls of cargo and mail. A regulated agent is defined in the Annex as an agent, freight forwarder or any other entity who conducts business with an operator and provides security controls that are accepted or required by the appropriate authority in respect of cargo or mail. There are five other provisions under Chapter 4.6 of Annex 17 pertaining to: the protection of cargo and mail from unauthorized interference from the point of screening or other security controls being applied until the departure of the aircraft; the non-acceptance of cargo or mail by operators unless it is confirmed that screening or other procedures have been applied and conformed by a regular agent; the appropriate screening of catering, stores and supplies intended for carriage by air; the appropriate screening of merchandise and supplies introduced into security restricted areas; and the fact that the security controls mentioned above have been implemented on the basis of a security risk assessment carried out by relevant national authorities.

If laws and practices are the glue that keeps air cargo security together, political will is the fuel which will ignites its progress and development. The thrust of political will essentially lies in a security culture that must be visible in every State. A security culture would make States aware of their rights and duties, and, more importantly, enable States to assert them. Those who belong to a security culture also know which conduct would compromise security and they are quick to educate and caution those who, out of ignorance, forgetfulness, or personal weakness, partake in insecure conduct. This security consciousness becomes a "culture" when all the 191 member States of ICAO as a whole make security violations socially and morally unacceptable within the group. In building a security culture within ICAO member States it is imperative that consideration should also be given to the development of a process for ensuring that all Member States are notified when deficiencies identified during the course of an ICAO security audit conducted under the Universal Security Audit Programme (USAP) remain unaddressed for a sustained period of time. A notification process could involve the use of information which does not divulge specific vulnerabilities but enables States to initiate consultations with the State of interest to ensure the continued protection of aviation assets on a bilateral basis. States have to adopt a security culture that admits of an overall approach to the threat as a potential harm to humanity. This should inevitably include strict adherence by States to the provisions of Annex 17. 


\section{Carriage by Air of Human Remains}

If a person dies in a country other than his own, there are no global rules or guidance that dictates the manner in which his remains could be transported back to his country, with dignity and care. This matter was highlighted in 2003 before the European Parliament with a real example of a British national who died while on holiday in Greece. The Greek authorities had carried out an autopsy which concluded that the deceased tourist had died of a heart attack. When the body was transported back home the deceased's family had requested a second autopsy, only to find that most of the deceased's organs had been removed in Greece after the autopsy and destroyed, according to Greek law. This had caused severe mental distress to the deceased's kin.

There are three dimensions to this subject: the health and sanitation aspects of carrying human remains by air; and the rights of close relatives of the deceased to bring his remains back home with speedy dispatch; and the risk of such carriage to aviation security. The former may have security implications as well as safety implications in that security clearance for this type of cargo has to be carefully ascertained and ensured. As this article will discuss, international standards for packaging bring to bear certain vulnerabilities in the acceptance of human remains for carriage by air.

There have been some concerns about human remains being used to transport explosives. The transportation Security Administration of the United States cautions consignors and consignees:

Out of respect to the deceased and their family and friends, under no circumstances will an officer open the container even if the passenger requests this be done. Documentation from the funeral home is not sufficient to carry a crematory container through security and onto a plane without screening. You may transport the urn as checked baggage provided that it is successfully screened. We will screen the urn for explosive materials/devices using a variety of techniques; if cleared, it will be permitted as checked baggage only. Crematory containers are made from many different types of materials, all with varying thickness. At present, we cannot state for certain whether your particular crematory container can successfully pass through an X-ray machine. However, we suggest that you purchase a temporary or permanent crematory container made of a lighter weight material such as wood or plastic that can be successfully X-rayed. ${ }^{2}$

There is a serious lacuna in regulatory consistency in the carriage by air of human remains which lays the thrust of Article 11 wide open. There have been some attempts by the international community to address the subject. The bottom line is that that, although several attempts have been made at international level in the past-some clear and some unclear-they lack unification and stand fragmented and ambivalent. To their credit, airlines, under the guidance of the International

\footnotetext{
${ }^{2}$ See Transportation Security Administration, Transporting the Deceased, at http://www.tsa.gov/ travelers/airtravel/specialneeds/editorial_1296.shtm.
} 
Air Transport Association (IATA), have adopted their own principles in carrying human remains with compassion and dedication. The conclusion suggests a way forward in binding the threads of this issue in a harmonious manner.

Human dignity is an international concept which is extended both to the living and the dead. The 1948 Universal Declaration of Human Rights of the United Nations - the cornerstone of human dignity — declares that the inherent dignity and the equal and inalienable rights of all members of the human family are the foundations of freedom, justice and peace in the world and that all human beings are born free and equal in dignity and rights. This statement establishes human dignity as the conceptual basis for human rights. $75 \%$ of the constitutions of ICAO's 191 member States use the concepts of "human dignity" or "personal dignity" explicitly. ${ }^{3}$ It follows therefore that if the remains of a human being are not given equal respect and dignity, the moral imperative of the doctrine of human dignity ${ }^{4}$ would be rendered destitute of meaning and purpose.

From an aviation perspective, most airlines in the world offer services for the transportation of human remains and cremated remains. These services are varied according to the policies of each airline, but all share a common thread of dedication and compassion in offering the service in the transportation of funeral shipments. Usually, airlines employ specially trained staff to address all the travelrelated issues that may arise when shipping such very sensitive cargo. The tasks assigned to these staff include providing advice to those seeking the airlines' services on applicable regulations, taking into account the delicateness of the responsibility that devolves upon the carrier.

In terms of property rights pertaining to a cadaver or other remains, such rights do not exist at common law. However, for the purpose of transportation-whether it be for embalming, cremation or internment - the corpse or cremated remains of a human being is considered to be property or quasi-property, the rights to which are held by the surviving spouse or next of kin. This right cannot be transferred and does not exist while the deceased is living. A corpse or urn carrying cremated remains may not be retained by either an undertaker or a carrier as security for unpaid funeral expenses, particularly if such were kept without authorization and payment was demanded as a condition precedent to its release. Upon burial the body accrues to the ground and any appurtenant property such as jewelry which was on the corpse on burial accrue to their rightful owner as determined by applicable principles of property laws and wills and testaments as they might exist.

The purpose of this article is to discuss de lege lata the fragmented regime applicable to the carriage by air of human remains. Two antiquated multilateral agreements, one Resolution and one Regulation all in Europe; some maundering by the ICAO Council decades ago; three Annexes to the Chicago Convention which may

\footnotetext{
${ }^{3}$ http://www.constitution.org; http://www.oefre.unibe.ch/law/icl; http://www.psr.keele.ac.uk.

${ }^{4}$ Human dignity has not been comprehensively defined and has remained a somewhat squishy subject, often explained theologically. However, the dictionary definition of dignity is that it is inter alia "the quality or state of being worthy of esteem or respect". See http://www.thefreedictionary.com/dignity.
} 
have applicability to this subject; some proactive guidelines by the International Air Transport Association and the World Health Organization and procedures and policy of individual air carriers comprise the history of this subject. Against this backdrop, this article will inquire into the need for a global regulatory process that would properly address this esoteric but important area of carriage by air.

\subsection{The Berlin Agreement of 1937}

The International Arrangement Concerning the Conveyance of Corpses ${ }^{5}$ (Berlin Agreement), signed at Berlin on 10 February 1937 was the first recorded attempt at the unification of rules relating to the carriage of human remains. The agreement, which applied to the international transport of corpses immediately after decease or exhumation, was designed to avoid the difficulties resulting from differences in the regulations concerning the conveyance of corpses, and recognized the necessity and the convenience of laying down uniform regulations in this area of transportation. Accordingly, the signatory States ${ }^{6}$ undertook to accept the entry into their territory, or the passage in transit through their territory, of the corpses of persons deceased in the territory of any one of the other Contracting countries upon certain conditions, which were incorporated in the Agreement.

The initial condition, as laid out in Article 1 of the Agreement was that, for the conveyance of any corpse by any means and under any conditions, a special laissezpasser be issued for a corpse which would state the surname, first name and age of the deceased person, and the place, date and cause of decease. The competent authority for the place of decease or the place of burial in the case of corpses exhumed had to issue the laissez-passer and it was recommended that the laissezpasser should be made out, not only in the language of the country issuing it, but also in at least one of the languages most frequently used in international relations.

The Berlin Agreement further stated that neither the country of destination nor the countries of transit shall require, over and above such papers as are required under international conventions for the purpose of transports in general, any document other than the laissez-passer referred to in Article 1. The following had to be presented to the competent authority for the issuance of laissez-passer: a certified true copy of the death certificate; and official certificates to the effect that conveyance of the corpse is not open to objection from the point of view of health or from the medico-legal point of view, and evidence that the corpse has been placed in a coffin in accordance with the regulations laid down in the Agreement. ${ }^{7}$

\footnotetext{
${ }^{5}$ League of Nations, Treaty Series 1938, No. 439r at 315-325.

${ }^{6}$ Germany, Belgium, Chile Denmark, Egypt, France, Italy, the Netherlands, Switzerland, Czechoslovakia and Turkey.

${ }^{7}$ Berlin Agreement, Airlines set for losses as mid-east unrest continues, Air Letter, No. 17,181, Friday, 25 February 2011at p. 3, Article 2.
} 
As for packaging the human remains, the Agreement, in Article 3 provided that corpses must be placed in a metal coffin, the bottom of which has been covered with a layer approximately $5 \mathrm{~cm}$. of absorbent matter such as peat, sawdust, powdered charcoal or the like with the addition of an antiseptic substance. Where the cause of decease was a contagious disease, the corpse itself was required to be wrapped in a shroud soaked in an antiseptic solution. A further requirement was that the metal coffin must thereupon be hermetically closed (soldered) and fitted into a wooden coffin in such a manner as to preclude movement. The wooden coffin was required to be of a thickness of not less than $3 \mathrm{~cm}$. and its joints must be completely watertight. It was also required that the coffin be closed by means of screws not more than $20 \mathrm{~cm}$. distant from one another, and strengthened by metal hoops. In the case of transport by air, The Agreement, in Article 7, required that coffins must be conveyed either in an aircraft specially and solely used for the purpose or in a special compartment solely reserved for the purpose in an ordinary aircraft.

The Agreement precluded bodies of persons who had died as a cause of plague, cholera, small-pox or typhus from being conveyed between the territories of the Contracting parties until the lapse of at least 1 year after the demise. No articles were permitted to be transported along with the coffin in the same aircraft or in the same compartment, other than wreaths, bunches of flowers and the like. ${ }^{8}$

\subsection{Agreement on the Transfer of Corpses (Strasbourg-1973)}

The second international agreement was in 1973 called the Agreement on the Transfer of Corpses, and it was drawn up within the Council of Europe by the European Public Health Committee. The Strasbourg Agreement was opened for signature by the member States of the Council of Europe on 26 October 1973. This agreement was designed to adapt the provisions of the Berlin Agreement concerning the conveyance of corpses, to the new situation arising from developments in the field of communications systems, international relations and commercial and tourist activities. A proposal to examine anew the problem of the transfer of corpses with a view to drawing up a new instrument was approved by the Committee of Ministers of the Council of Europe in 1967 and this task was entrusted to the European Public Health Committee which, in the course of its work, gave due consideration to the observations, among others, of the European Federation of Funeral Directors (Brussels) and the European Funeral Directors Association (Vienna). The text of the draft Agreement was submitted to the European Committee on Legal Co-operation (CCJ) before its final adoption by the Committee of Ministers of the Council of Europe in April 1973. It was opened for signature by member States of the Council of Europe on 26 October 1973.

${ }^{8} I d$. Article 4. 
The Strasbourg Agreement defines the transfer of corpses as the international transport of human remains from the State of departure to the State of destination. Accordingly, the State of departure is that in which the transfer began; in the case of exhumed remains, it is that in which burial had taken place; the State of destination is that in which the corpse is to be buried or cremated after the transport. The Agreement does not apply to the international transport of ashes. Article 3 of the Agreement states that during the transfer, any corpse is required to be accompanied by a special document (laissez-passer for a corpse) issued by the competent authority of the State of departure. The laissez-passer has to include at least the information set out in the model annexed to the Agreement; and be made out in the official language or one of the official languages of the State in which it was issued and in one of the official languages of the Council of Europe.

Article 4 provides that, with the exception of the documents required under international conventions and agreements relating to transport in general, or future conventions or arrangements on the transfer of corpses, neither the State of destination nor the transit State shall require any documents other than the laissez-passer for a corpse. The laissez-passer is issued by the competent authority referred to in Article 8 of the Agreement, ${ }^{9}$ after it has been ascertained that: all the medical, health, administrative and legal requirements of the regulations in force in the State of departure relating to the transfer of corpses and, where appropriate, burial and exhumation have been complied with; the remains have been placed in a coffin which complies with the requirements laid down in Articles 6 and 7 of the Agreement; and that the coffin only contains the remains of the person named in the laissezpasser and such personal effects as are to be buried or cremated with the corpse.

Article 6 requires that the coffin must be impervious and that the inside must contain absorbent material. If the competent authority of the State of departure consider it necessary the coffin must be provided with a purifying device to balance the internal and external pressures. It may consist of: either an outer coffin in wood with sides at least $20 \mathrm{~mm}$ thick and an inner coffin of zinc carefully soldered or of any other material which is self-destroying; or a single coffin in wood with sides at least $30 \mathrm{~mm}$ thick lined with a sheet of zinc or of any other material which is selfdestroying. If the cause of death is a contagious disease, the body itself is required to be wrapped in a shroud impregnated with an antiseptic solution.

Article 6 further provides that the coffin, if it is to be transferred by air, has to be provided with a purifying device or, failing this, present such guarantees of resistance as are recognised to be adequate by the competent authority of the State of departure. If the coffin is to be transported like an ordinary consignment, it has to be packaged so that it no longer resembles a coffin, and it shall be indicated that it be handled with care. ${ }^{10}$

\footnotetext{
${ }^{9}$ Article 8 states that each Contracting Party shall communicate to the Secretary General of the Council of Europe the designation of the competent authority referred to in Article 3, paragraph 1, Article 5 and Article 6, paragraphs 1 and 3 of the Agreement.

${ }^{10}$ Article 7 of the Strasbourg Agreement.
} 


\subsection{Resolution 2003/2032 (INI)}

The European Community was dissatisfied with both the Berlin Agreement and the Strasbourg Agreement (which only some member States had signed), claiming that these Agreements advocated indirect discrimination by providing for non-European Community residents. Also it was claimed that these two agreements imposed strict rules on the cross-border transfer of mortal remains, applied essentially to "nonnationals" and hence ran counter to the Community scheme of things. Accordingly, and with a view to addressing the case where a Community citizen expired in a Community country other than his own and his remains had to be repatriated to his country, a Committee was appointed by the European Parliament to consider an instrument that addressed the conveyance of mortal remains suggested in 2003 Resolution 2003/2032 (INI). This Resolution noted that, on account of the above agreements, the death of a Community citizen in a Member State other than his country of origin results in more complex procedures, a longer period of time before burial or cremation takes place and higher costs than if the death had occurred in the deceased person's country of origin,

Another compelling reason for this Resolution was the recognition that, in view of the growth in intra-Community tourism, the increasing numbers of retired people who choose to live in a country other than their own and, more generally, greater intra-Community mobility which is actually encouraged, the number of Community citizens who die in a country other than their country of origin was bound to increase. This was considered against the backdrop that Community citizens should, mutatis mutandis, be able to move between and reside in Member States in similar conditions to nationals of a Member State moving around or changing their place of residence in their own country, and that exercising the right to freedom of movement and freedom of residence should be facilitated to the utmost by reducing administrative formalities to an absolute minimum.

The European Community was of the view that, at the time the Resolution was proposed, it was still far from true that a Community citizen who dies in a Member State other than his own is treated in the same way as a national who dies in his home country. For example, the fact that a zinc coffin is required for the repatriation of a corpse from Salzburg to Freilassing (a distance of $10 \mathrm{~km}$ ) but not for the transfer of a body from Ivalo to Helsinki (a distance of 1,120 km) (2).

Therefore it was pointed out that the repatriation of mortal remains without excessive cost or bureaucracy in the event of the death of a European Community citizen in a country other than the one in which either burial or cremation was to take place may be regarded as a corollary of the right of each EU citizen to move and reside freely within the territory of the Member States.

The Resolution called upon the Commission to see that the standards and the procedures applied in the cross-border transportation of corpses were harmonized throughout the Community and to endeavor to ensure that, as far as possible, Community citizens were treated in the same way as nationals in their home country. 
A Regulation, covering intra-community transport of bodies according to the European Standard CEN/BT/TF 139 on Funeral Services and approved on 27 July 2005 goes on to say in Article 1 that the identification of the deceased must be performed before the body is placed in the coffin by the funeral enterprise or operator of the country of departure. The elements of identification relate to the civil status of the deceased and are indicated on the laissez-passer for the body. For identification, the body must be provided with: an identification bracelet attached to the body part (wrist, ankle...,); and a non-removable and tamperproof identification tag attached to the coffin and its wrapping, if any. The information required on the bracelet were: surname and first name(s); sex; date and place of birth; date and place of death; and nationality. The information required on the identification tag were to be: surname and family name(s); date of birth; and date of death.

Article 2 of the Regulation required that the coffin or casket that carried the remains must be made of solid material — the main material used in Europe being wood (excluding the use of carton or chipboard). The material used for the coffin must be biodegradable. It also required that the coffin must be impervious; the products used to make it impervious must be biodegradable and in conformity with the standards applicable to crematorium emissions. In particular, the coffin must be impervious to decomposition liquids and fitted with absorbent material. The out cover of the coffin/casket was required to meet necessary sanitary requirements.

The Regulation had chemical requirements that were not contained in the 1937 Berlin Agreement and the 1973 Strasbourg Agreement. For instance, Articles 2.3 and 2.5, specified conditions for international carriage of corpses by providing that if the cause of death was a contagious disease (as per the WHO official list), the outer container (usually wooden) used for the transport of the body may be lined with a hermetically sealed container. The hermetically sealed container must be provided with a purifying filter. If the consecutive treatments (thanatopraxy) have been performed within $36 \mathrm{~h}$ after the death the body must be encoffined within 6 days. The transport must be done not more than $48 \mathrm{~h}$ after encoffining and sealing. The conditions required for long distance international transport outside Europe under the Agreement were: hermetically sealed container; and/or embalming/thanatopractical treatment; and/or refrigeration. In the case of refrigeration at no time shall the temperature inside the container exceed $80{ }^{\circ} \mathrm{C}$ during transport.

The Regulation requires two types of documents for carriage of corpses: medical certificate upon death; and a laissez passer. The medical certificate is required to be drawn up, on the one hand, in the language of the country of departure in which the death had occurred and, on the other hand, in one of the following languages: English, German or French. It must contain information relating to the deceased such as: surname and maiden name in the case of a married woman; first name(s); date and place of birth; date and place of death; sex; and cause of death. 


\subsection{ICAO Initiatives}

\subsubsection{The Council}

The Council of ICAO, at its Thirty Second Session in 1957 addressed the carriage under the heading "Carriage of Sick Persons, Pregnant Women, Live Animals and Coffins-Sanitation on Board Aircraft" at which IATA recommended that in addition to the prevailing requirement - that human remains be placed in hermetically-sealed coffins which are enclosed in outside cases - human remains should be embalmed prior to being placed in the coffin. IATA further suggested that acceptance of such coffins is dependent upon the type of aircraft, requirements of entry and clearance and prior approval of the countries of origin, transit and destination. ${ }^{11}$ The Council noted that comments on the carriage of coffins had been received from twenty seven States (from a total of 72 member States at that time) and two overseas territories. Three of these States reported that they were bound by the provisions of the 1937 Berlin Agreement and Eight States advised ICAO that the carriage of corpses existed in their national legislations. Thirteen States commented that they had not, in their experience encountered serious difficulties in this area. The United States made the comment:

Because of known effects of rare atmosphere at high altitude on sealed caskets, such caskets should not be carried by aircraft. ${ }^{12}$

The ICAO Secretariat responded in assent:

Differences in atmospheric pressure are known to have caused bursting of coffins, particularly when sealed hermetically (by welding) according to provisions of Articles 5 and 7 of the Berlin Arrangement, or similar provisions in national legislation. Prompted by rapid decomposition in flight, such transports occasionally arrive in appalling conditions; in some States (Australia, Philippines, Venezuela, Netherlands Antilles), therefore, it is required that corpses be embalmed prior to air transport, thus eliminating at least certain difficulties. If some pressure-relief system were applied to sealed caskets, the difficulties caused by pressure differences might disappear, but international transport would not permitted by existing laws.

It is noteworthy that during these discussions, cremated human remains were not mentioned, except by Belgium which said that "incinerated corpses are accepted without any restrictions and are carried on all types of aircraft". ${ }^{13}$ The ICAO Council concluded that the difficulties reported by States were caused by variations of atmospheric pressure; a characteristic of transport by air, while for international transport coffins must be hermetically sealed.

ICAO has approached this subject from another dimension i.e. the carriage of human remains of an aircraft accident victim. In 2001 the Council released its Guidance on Assistance to Aircraft Accident Victims and their Families ${ }^{14}$ where

\footnotetext{
${ }^{11} \mathrm{C}-\mathrm{WP} / 2448,5 / 6 / 57$, Addendum and Corrigendum, 21/11/576 at 3.

${ }^{12} I d$. Paragraph 20.1 at p. 10.

${ }^{13} \mathrm{C}-\mathrm{WP} / 2448,5 / 6 / 57,42$ tit.24, pr 22 S 4, Appendix "A" at 25.

${ }^{14}$ Guidance on Assistance to Aircraft Accident Victims and their Families, ICAO Circular $285-A N / 166$.
} 
ICAO recognizes that in an accident context the identification, custody and return of human remains are very important forms of family assistance but remains are often difficult to recover and identification can be an arduous and time consuming process. The ICAO guidance goes on to say that legislation often requires a post mortem examination of those killed in an accident and in some instances there may be remains that cannot be identified. ${ }^{15}$ ICAO also calls for personal effects of the deceased to be correctly handled and returned to their lawful owners. ${ }^{16}$ The Guidance also calls for the State of occurrence to provide for the return of human remains ${ }^{17}$ while also devolving that burden —of the carriage of such remains—upon the aircraft operator involved in the accident. ${ }^{18}$

\subsubsection{Annexes 9, 17 and 18 to the Chicago Convention}

There are three Annexes to the Chicago Convention which bear some relevance to the carriage of human remains by air-Annex 9 (Facilitation), Annex 17 (Security) and Annex 18 (The Safe Transport of Dangerous Goods by Air). The Annex 9 definition of cargo implies that human remains could be categorized as cargo by giving the definition of cargo as "any property carried on an aircraft other than mail, stores and accompanied or mishandled baggage. This definition is slightly different from the one contained in another ICAO document-Technical Instructions for the Safe Transport of Dangerous Goods by Air ${ }^{19}$ which defines "cargo" as "any property carried on an aircraft other than mail and accompanied or mishandled baggage. Annex 18 does not define the word "cargo" but defines "dangerous goods" as articles or substances which are capable of posing a risk to health, safety, property or the environment and which are shown in the list of dangerous goods in the Technical Instructions or which are classified according to those instructions. The Technical Instructions do not list human remains as being dangerous cargo. However, it behooves the international aviation community to inquire, along the lines of ICAO discussions in the Council, whether human remains could be ruled out as not posing a risk to health or the environment under any circumstances of carriage by air or whether human remains, depending on the way it is packed for transport, could be considered as dangerous goods. ${ }^{20}$

Standard 4.6.1 of Annex 17 requires each Contracting State to ensure that appropriate security controls, including screening where applicable, are applied to cargo and mail, prior to their being loaded onto an aircraft engaged in passenger commercial air transport operations. The operative words here are "security

\footnotetext{
${ }^{15}$ Id. Paragraph 3.10.

${ }^{16} I d$. Paragraph 3.11.

${ }^{17} I d$. Paragraph 5.1.

${ }^{18} I d$. Paragraph 5,7.

${ }^{19}$ ICAO Doc 9284, AN/905 (2011-2012 Edition).

${ }^{20}$ American Airlines requires that human remains packed in dry ice are subject to dangerous goods regulations. https://www.aacargo.com/shipping/humanremains.jhtml.
} 
controls" which brings to bear the reality that different States could have different security controls ${ }^{21}$ and that they should be harmonized in ensuring supply chain security and global security standards. Screening and examination of cargo and mail are paramount to this consideration.

Standard 4.6.2 requires that each Contracting State establish a supply chain security process, which includes the approval of regulated agents and/or known consignors, if such entities are involved in implementing screening or other security controls of cargo and mail. A regulated agent is defined in the Annex as an agent, freight forwarder or any other entity who conducts business with an operator and provides security controls that are accepted or required by the appropriate authority in respect of cargo or mail. There are five other provisions under Chapter 4.6 of Annex 17 pertaining to: the protection of cargo and mail from unauthorized interference from the point of screening or other security controls being applied until the departure of the aircraft ${ }^{22}$; the non-acceptance of cargo or mail by operators unless it is confirmed that screening or other procedures have been applied and conformed by a regular agent ${ }^{23}$; the appropriate screening of catering, stores and supplies intended for carriage by air $^{24}$; the appropriate screening of merchandise and supplies introduced into security restricted areas ${ }^{25}$; and the fact that the security controls mentioned above have been implemented on the basis of a security risk assessment carried out by relevant national authorities. ${ }^{26}$

Getting back to Annex 9, there is a whole chapter in the Annex-Chapter 4dedicated to the entry and departure of cargo and other articles. Surprisingly, there is no provision in the Annex for priority of clearance or transport of human remains over other cargo, despite the prominence given to the subject in ICAO Circular 285-AN/166. ${ }^{27}$ Another surprise is that, although there is a Recommended Practice in the Annex which suggests that electronic information systems for the release and clearance of "goods" (my emphasis) should cover their transfer between air and other modes of transport, ${ }^{28}$ there is no definition of "goods" in the Annex. Do corpses or cremated human remains come under the purview of "goods"? This question is valid in the context of Appendix 3 to the Annex which has a template for a cargo manifest where there exists a column for "Nature of Goods". There is no mention of the word "cargo" in this template.

\footnotetext{
${ }^{21}$ Annex 17 defines a security control as "a means by which the introduction of weapons, explosives or other dangerous devices, articles or substances which may be used to commit acts of unlawful interference can be prevented.

${ }^{22}$ Standard 4.6.3.

${ }^{23}$ Standard 4.6.4.

${ }^{24}$ Standard 4.6.5.

${ }^{25}$ Standard 4.6.6.

${ }^{26}$ Standard 4.6.7.

${ }^{27}$ Baldwin (1910), 97.

${ }^{28}$ Annex 9 to the Convention on International Civil Aviation, Thirteenth Edition: July 2011, Recommended Practice 4.18.
} 
In view of the above discussion it might be worthwhile for a detailed discussion on the status of human remains in the global aviation context and a re-visit of the 1957 discussions in the ICAO Council. The added dimension of related ICAO documentation such as Circular 285-AN/166 makes it all the more compelling.

\subsubsection{IATA, WHO and United States Guidelines}

The International Air Transport Association has clear, cogent guidance on the carriage by air of human remains. In its Airport Handling Manual (AHM) IATA prescribes that for special cargo, such as valuable cargo, perishables, vulnerable cargo, human remains and shipments of special importance or urgency, particular points to be considered are: that all personnel concerned are made fully aware of the nature and handling requirements of all such shipments; suitable arrangements are made for the security of valuable and vulnerable cargo; perishables are handled in accordance with the requirements of the particular commodity and in particular the most recent edition of the Perishable Cargo Regulations Manual; that a check is made to ensure that the final load assembled for dispatch to the aircraft does include shipments of special importance or urgency; and that shipments considered as special cargo have "special consignment" labels visibly attached to each package. ${ }^{29}$

The IATA Ground Operations Manual (IGOM) provides that human remains should be carried in an aircraft only if accepted by the operating airline for transport. The IGOM requires the carrier to make sure that a Human Remains Acceptance Checklist has been used (if required by the operating airline). Carriers are required, according to the IGOM, not to accept any human remains that are consolidated with any cargo other than other human remains. With regard to cremated human remains the Manual requires that only urns or other suitable containers as cargo with no special restrictions are accepted for carriage and that the carrier should make sure that the urn or other container is packed in a neutral outer pack that will protect the urn from breakage and/spillage. ${ }^{30}$ It also prescribes that human remains in coffins should not be stored next to food or live animals, adding that there appears to be no scientific or technical reason why live animals and human remains should be segregated in aircraft cargo compartments, except that it may be ethical for cultural reasons to segregate them.

IATA in AHM 333 states that, should a body fluid leakage occur while transporting dead bodies, the usual accepted guidelines endorsed by WHO for dealing with spilled body fluids should be followed and the handler is advised to: wear disposable gloves and, if available, a plastic apron. If the spillage has occurred on an aircraft, the AHM provision advises the handler to only use cleaning materials suitable for aircraft use. He should not try to clean the body fluids by hosing with water or air and should use material that will adsorb the body fluids and scrape the material into a biohazard bag. Afterwards, he should wash the area with water/ disinfectant after removal of the adsorbent material, dispose of gloves and apron in a biohazard bag and wash hands thoroughly with soap and water afterwards.

\footnotetext{
${ }^{29}$ IATA Airport Handling Manual, AHM 310 at 149.

${ }^{30}$ IATA IGOM, Chapter 3.
} 
WHO has also some guidance pertaining to the handling of human remains, and recommends as a fundamental measure that the handling of human remains should be kept to a minimum. Additionally, WHO recommends, particularly in the case of deaths caused by infectious diseases that remains should not be sprayed, washed or embalmed and that only trained personnel should handle remains during the outbreak. Personnel handling remains should wear personal protective equipment (gloves, gowns, apron, surgical masks and eye protection) and closed shoes. ${ }^{31}$

In the United States, there are no requirements for importation into the country if human remains consist entirely of: clean, dry bones or bone fragments or human hair; teeth; fingernails or toenails; and human remains that are cremated before entry into the United States. Human remains intended for interment or subsequent cremation after entry into the United States must be accompanied by a death certificate stating the cause of death. If the death certificate is in a language other than English, then it should be accompanied by an English language translation.

If the cause of death was a quarantinable communicable disease (i.e., cholera, diphtheria, infectious tuberculosis, plague, smallpox, yellow fever, viral hemorrhagic fevers, SARS, or pandemic influenza), the remains must meet the applicable standards and may be cleared, released, and authorized for entry into the United States only if: the remains are cremated; or the remains are properly embalmed and placed in a hermetically sealed casket; or the remains are accompanied by a permit issued by the Director of the Centre for Disease Control and Prevention (CDC). The CDC permit (if applicable) must accompany the human remains at all times during shipment. If the cause of death was anything other than a quarantinable communicable disease, then the remains may be cleared, released, and authorized for entry into the United States if: the remains meet the standards for applicable or properly embalmed and placed in a hermetically sealed casket, or are accompanied by a permit issued by the CDC Director); or the remains are shipped in a leak-proof container.

Federal quarantine regulations (42 CFR Part 71) state that the remains of a person who is known or suspected to have died from a quarantinable communicable disease may not be brought into the United States unless the remains are; properly embalmed and placed in a hermetically sealed casket, cremated, or accompanied by a permit issued by the CDC Director. Quarantinable communicable diseases include cholera; diphtheria, infectious tuberculosis; plague; smallpox, yellow fever; viral hemorrhagic fevers (Lassa, Marburg, Ebola, Congo-Crimean, or others not yet isolated or named); severe acute respiratory syndrome (SARS); and influenza caused by novel or re-emergent influenza viruses that are causing or have the potential to cause a pandemic. A CDC permit may be required when the remains are not embalmed or cremated, especially if the person is suspected or known to have died from a communicable disease.

Persons wishing to import human remains, including cremated remains, into the United States must obtain clearance from CDC's Division of Global Migration and Quarantine (DGMQ). Clearance can be obtained by presenting copies of the foreign

\footnotetext{
${ }^{31}$ Interim Infection Control Recommendations for Care of Patients with Suspected or Confirmed Filovirus (Ebola, Marburg) Haemorrhagic Fever, BDP/EPR/WHO, Geneva March 2008.
} 
death certificate and if needed, a CDC/DGMQ permit to the CDC Quarantine Station with jurisdiction for the U.S. port of entry. A CDC/DGMQ permit may be needed to import human remains if the deceased is known or suspected to have died from a quarantinable communicable disease. A copy of the foreign death certificate and the CDC/DGMQ permit must accompany the human remains at all times during shipment. The foreign death certificate should state the cause of death and must be translated into English.

The basic principle that should apply to the handling of human remains must be consistent with the policy which currently applies in case of aircraft accident investigations, in that the country in which the death occurred must act contemporaneously and in close consultation with the country of nationality. This would obviate the case of the British tourist who died in Greece. The second principle should be that the principles of ICAO Circular 285-AN/166 should be incorporated into Annex 9 along with a Standard in Chapter 4 that human remains should be accorded priority and dignity and that specially reduced rates should be promulgated by States on their airlines for this purpose. This Standard should be adopted in accordance with the basic philosophy of Article 44 (d) of the Chicago Convention which states that ICAO should strive to meet the needs of the people of the world for safe, regular, efficient and economical air transport.

Annex 9 should contain a separate Appendix for the carriage of human remains by air, which would lay down global principles for the handling, care and commitment that States could ensure. This Appendix should have a cross reference to Annex 18 and the Technical Instructions contained in Doc $9284^{32}$ with appropriate linkages that ensure the harmonious application of both Annexes to this sensitive subject.

As for Annex 18, a study should be undertaken to determine as to when a cadaver or cremated remains would, if at all, become a dangerous good. The focus area would be both on the condition the human remains are at the point of acceptance for carriage, and the manner in which they are packaged. In the ultimate analysis, there has to be core global rules in place for this important area of air transportation. It cannot be left for individual States or airlines to decide.

Enhancing global civil aviation security and facilitation is one of ICAO's Strategic Objectives as adopted by the Council in May 2012. This is the first time facilitation has been mentioned in ICAO's strategic language and it should be a harbinger of new studies and new cooperation with the international community between ICAO and its member States o the carriage by air of human remains.

\section{References}

Baldwin SE (1910) The law of the airship. Am J Int Law 4(95):97

Dobson C, Payne R (1987) Appendix B: the chronology of terror: 1968-1987. In: War without end: the terrorists: an intelligence dossier. Sphere Books, London

\footnotetext{
${ }^{32}$ Dobson and Payne (1987), p. 53.
} 